\title{
The Use of Neuroprotective Agents in Treating Geographic Atrophy
}

\author{
Hendrik P.N. Scholl ${ }^{a} b$ David Boyer ${ }^{c}$ Andrea Giani ${ }^{d}$ Victor Chong ${ }^{d}$ \\ anstitute of Molecular and Clinical Ophthalmology, Basel, Switzerland; ${ }^{b}$ Department of Ophthalmology,

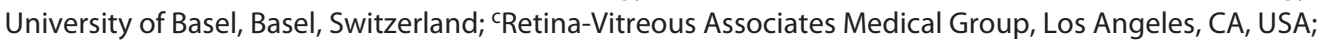 \\ ${ }^{\mathrm{d}}$ Boehringer Ingelheim International $\mathrm{GmbH}$, Ingelheim am Rhein, Germany
}

\section{Keywords}

Geographic atrophy · Neuroprotection · Age-related macular degeneration $\cdot$ Retina $\cdot$ Neurotrophic factors

\begin{abstract}
Geographic atrophy (GA) secondary to age-related macular degeneration accounts for close to one-quarter of cases of legal blindness in the USA and the UK. Despite this notable disease burden, the pathophysiology of GA is complex and not fully understood, and there is currently no approved treatment to prevent or slow its progression. GA is heterogeneous in its appearance and extent, and underlying associated traits such as drusen and complement factor polymorphisms vary between patients and by ethnicity, posing a challenge for treatment development. The root cause of vision loss in GA is photoreceptor death; therefore, protecting photoreceptors from damage and delaying their degeneration are key to successful GA treatment. There are multiple neuroprotective pathways that may contribute to protecting photoreceptors from damage, and compounds that target these pathways include antioxidants, neurotrophic factors, and catalases. However, the efficacy of previously trialled neuroprotective therapies in GA, such as brimonidine, tandospirone, and NT-501, has been inconsistent; this may
\end{abstract}

be due to their target of action, method of delivery, and/or suboptimal duration of action. Neurotrophic factors, or molecules involved in neuroprotective signalling cascades, may be ideal agents for further investigation for the treatment of GA. Future neuroprotective strategies in GA must focus on the development of agents with a long duration of action that can combat the progression of chronic damage in GA to provide clinically meaningful benefits for patients.

(C) 2021 The Author(s)

Published by S. Karger AG, Basel

\section{Introduction}

Epidemiology of Geographic Atrophy

Age-related macular degeneration (AMD) is a leading cause of blindness in people aged 50 years and over in the developed world [1-4]. The incidence of AMD and its advanced stages increases exponentially with age [4]; as the global population ages, it is estimated that the prevalence of advanced AMD will rise from 11.26 million cases in 2020 to 18.57 million by $2040[4,5]$.

Advanced AMD can be divided into 2 forms: "wet" AMD (wAMD) and geographic atrophy (GA). wAMD is characterized by the formation of new blood vessels from the choroid into the subretinal or retinal pigment epithe-
(C) 2021 The Author(s)

Published by S. Karger AG, Basel

This article is licensed under the Creative Commons Attribution 4.0 International License (CC BY) (http://www.karger.com/Services/ OpenAccessLicense). Usage, derivative works and distribution are permitted provided that proper credit is given to the author and the original publisher.
Correspondence to:

Hendrik P.N. Scholl, hendrik.scholl@iob.ch 
lium (RPE) spaces and comprises 3 primary types [6-8]. GA is characterized by progressive atrophy and thinning of the RPE and choriocapillaris, leading to photoreceptor death and vision loss [5, 9-11]. At present, GA affects approximately 5 million people globally, accounting for roughly $25 \%$ of cases of legal blindness in the USA and the UK $[5,12]$. A meta-analysis published in 2020 indicated that GA is less common in Asian populations compared with European populations, although information on the epidemiology of GA in Asia is limited [13].

\section{Pathophysiology of GA}

Although heterogeneous in its appearance and extent, GA often begins as a single parafoveal lesion $[14,15]$. GA may form in areas previously occupied by drusen or RPE detachments [14, 16-18]; drusen are extracellular deposits that are located between the RPE and Bruch's membrane [10]. The presence of multiple large drusen increases the probability of developing GA [5], and GA that forms in areas previously occupied by drusen is associated with substantially worse visual outcomes [14]. GA is also associated with morphological changes such as reticular pseudodrusen $[16,18]$, which are small yellowwhite lesions typically located above the RPE [18]. Reticular pseudodrusen have been associated with reduced choriocapillaris flow and density [18] and are more common in eyes with GA or type 3 wAMD (retinal angiomatous proliferation) than those with other advanced forms of AMD ( $83 \%$ and $50 \%$ of eyes respectively, vs. 9\%) [19]. Eyes with reticular pseudodrusen are more likely to progress to an advanced form of AMD than those with drusen alone [20-22]. The presence of drusenoid pigment epithelial detachments may also precipitate GA, with one analysis showing that drusenoid pigment epithelial detachments have a $50 \%$ chance of developing into GA after 7 years [23].

Complement factor polymorphisms are associated with, and are systemically activated in, AMD [24-28]. The complement system is a crucial part of the body's immune system, leading to proteolytic cascades and the release of proinflammatory molecules that target pathogens, resulting in inflammation $[28,29]$. Chronic inflammation has been associated with the pathogenesis of GA [30]. Furthermore, complement activation may play a functional role in systemic cardiovascular disease, leading to poor choroidal and ocular perfusion, which could precipitate GA [31, 32]. Although complement is not associated with all cases of GA, one phenotypic subgroup of GA (with large soft drusen and foveal atrophy) is characterized by a high genetic risk score for complement poly-

Neuroprotective Agents in Geographic Atrophy morphisms [33], and complement proteins have been found in the retina adjacent to some GA lesions [10]. Components of the complement system have been found in drusen, but to date, their relationship with pseudodrusen is less clear [34]. It is also not currently known whether complement proteins lead to the formation of drusen or accumulate as a result of drusen [28]. The presence and phenotype of drusen and pseudodrusen vary by race; for example, Caucasians are more likely to develop large drusen than people of other races $[35,36]$. Similarly, the complement polymorphisms that are commonly found in Caucasians have a much lower frequency in Asian populations [37-40]. Ethnic variation in the AMD-associated $\mathrm{Y} 402 \mathrm{H}$ complement polymorphism does not correlate with the overall prevalence of AMD, suggesting that different polymorphisms or genes may be risk factors in some populations [40]. Two phenotypic subgroups of GA with low genetic risk scores for complement polymorphisms have been identified: one with foveal atrophy and few drusen, and another with extrafoveal atrophy, reticular pseudodrusen, and a high ARMS2 genetic risk score [33]. This suggests that the complement system and drusen phenotype are not major drivers of AMD in all populations.

Trials of complement inhibition in patients with GA have shown inconsistent success in slowing GA progression; only pegcetacoplan and avacincaptad pegol have demonstrated a significant reduction in square root GA lesion growth versus sham treatment $(0.39$ vs. $0.49 \mathrm{~mm}$, $p=0.044 ; 0.32$ vs. $0.44 \mathrm{~mm}, p=0.0051$, respectively), but neither were accompanied by a corresponding functional difference in best corrected visual acuity (BCVA) or lowluminance BCVA [41-45]. The limited success of complement inhibitors may partly relate to the ethnic variation in complement polymorphisms.

\section{Disease Burden of GA}

GA is associated with considerable disease progression and burden, with patients experiencing a loss of both visual acuity and independence when performing daily tasks. Close to half of all patients with GA are legally blind, with $42 \%$ reported as having $20 / 200$ vision or worse [46]. Larger areas of GA are associated with a decreased visual acuity and function, hindering patients' ability to carry out daily tasks [47-50]. Reading speed declines as a function of GA lesion size, location, and growth [50,51], and GA negatively affects patients' ability to recognize faces $[52,53]$. GA also severely impacts patients' ability to drive, limiting their freedom to travel [54]; $66.7 \%$ of patients become ineligible to drive within a median time of 
1.6 years from their diagnosis [12]. AMD and GA also affect other aspects of patients' quality of life, increasing the risk of depression as well as susceptibility to falls and injuries due to poor visual acuity $[55,56]$. As a GA lesion increases in size, skills critical for maintaining quality of life deteriorate, such as reading speed and recognizing faces $[50,51,57]$. Many patients with GA also experience fear related to their condition and the deterioration of their eyesight $[48,49]$.

\section{Unmet Medical Need}

Although acute vision loss due to wAMD responds to treatment and is reversible to some extent, the progressive vision loss that results from GA is irreversible in a substantial proportion of treated patients $[8,9]$. As such, the primary goal of GA treatment is to prevent or delay disease progression [58]. Some large trials such as the Age-Related Eye Disease Studies (AREDS/AREDS2) focused on the prevention of advanced AMD [59-61] but included only a small number of patients with GA, yielding little benefit for this population. For example, AREDS included 118 patients with GA, compared with 658 with wAMD and 1,568 with large or extensive drusen [60].

At present, there is no approved pharmacological treatment for preventing the onset or slowing the progression of GA. The slow progress of treatment development may in part be attributed to the lack of adequate in vivo models of GA [62]. In addition, most clinical trials that focused specifically on patients with GA have targeted the complement system. However, the presence of reticular drusen and complement activation vary by population, meaning that anti-complement therapy may not be efficacious in all patients with GA [63-65]. This has prompted investigation into alternative approaches, including anti-inflammatory agents, synthetic vitamin A replacement therapy, visual cycle modulation, and neuroprotection [66-71]. To examine the potential role of neuroprotective treatments in GA, we investigated peerreviewed journal articles using PubMed and conducted a series of clinical trial database searches using clinicaltrials.gov for studies of GA treatments.

\section{Neuroprotection in GA}

\section{Background of Neuroprotection}

Neuroprotection entails the preservation, recovery, or regeneration of neuronal function and structure after catastrophic acute injury (e.g., stroke) or chronic ongoing damage (e.g., neurodegeneration) $[72,73]$. Although the symptoms of disease resulting from neural damage vary, many aspects of their pathogenesis are shared, such as inflammation and oxidative stress [74-77]. Investigation into the pharmacological protection of neurons from damage began in the 1980s and focused on stroke and excitotoxic injury [78].

Multiple complex pathways for neuroprotection exist, including the inhibition of neurodegenerative apoptosis, necroptosis, and ferroptosis [79-81]. As such, there are many potential therapeutic approaches for neuroprotection (shown in Fig. 1). These include apelin-13 peptide, which has been shown to protect against further acute damage in a rat model of ischemic stroke through the AMPK/GSK-3 $\beta$ pathway via AR/Ga/PLC/IP3/CaMKK signalling [82], and $N$-acetyl-serotonin treatment, which protects ischemic neural cells in a state of oxygen-glucose deprivation from chronic damage by inhibiting mitochondrial cell death in mice [83]. In addition, the PI3K/ Akt pathway is critical in the protection of neural cells against staurosporine-induced apoptosis through the upregulation of tropomyosin-related kinase (Trk) via nerve growth factor and brain-derived neurotrophic factor (BDNF) in vitro [84]. It is clear that there are many potential mechanisms through which neuroprotection can be achieved.

\section{Antioxidants}

Antioxidants may delay or prevent apoptosis, thus preserving neurons $[76,85]$. Manganese superoxide dismutase is thought to be a major mechanism by which cells counteract reactive oxygen species (ROS) injury after ischemia [86]. A synthesized mimic of manganese superoxide dismutase significantly increased the in vitro viability of neurons and improved neurological function in an ischemic stroke mouse model $(p<0.01$ compared with an untreated control group) [86]. Resveratrol and glutathione have also been investigated for their potential neuroprotective effects in retinal ganglion cells $[76,87,88]$. To date, in humans, antioxidants have not been shown to have a significant effect on GA lesion growth; the placebo group in AREDS had a mean lesion growth of $7.89 \mathrm{~mm}$, whereas patients who received antioxidants alone had a mean lesion growth of $6.64 \mathrm{~mm}(p=0.19)$ [89]. Furthermore, a trial of OT-551 (a synthesized molecule with antioxidant properties administered via eye drop) failed to show any significant difference in area of GA or drusen between the study and fellow eye $(p>0.05)$ [90]. However, the use of antioxidants, whether through diet or other modern therapeutic methods, could stimulate endogenous protective mechanisms in patients with GA [85]. 


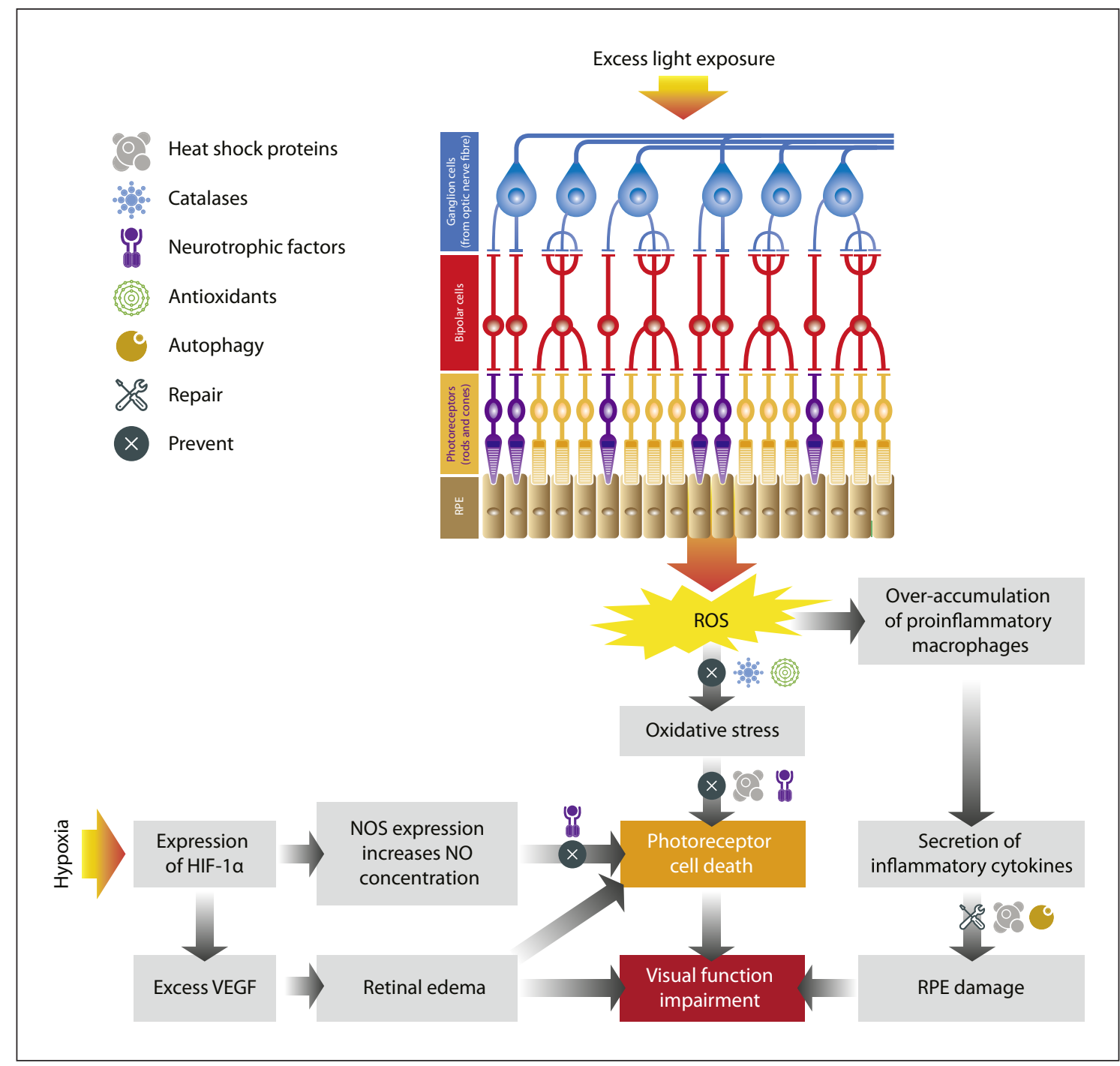

Fig. 1. Mechanisms of neural damage and neuroprotection. HIF, hypoxia inducible factor; NO, nitric oxide; NOS, nitric oxide synthase; ROS, reactive oxygen species; RPE, retinal pigment epithelium; VEGF, vascular endothelial growth factor.

Neurotrophic Factors

Neurotrophic factors are involved in regulating the development and function of the nervous system [91] and have neuroprotective effects [84]. Ciliary neurotrophic factor (CNTF) gene therapy has been shown to confer life-long neuroprotection to photoreceptors in a mouse model [92] and can both suppress photoreceptor death and stimulate Müller glial cell proliferation [93]. However, BDNF in combination with tyrosine receptor kinase B (TrkB) gene therapy may be a more potent neuroprotector than CNTF alone; in a rat model, $76 \%$ of BDNF-treated retinal ganglion cells that had undergone TrkB gene transfer survived post-axotomy, when typi- cally over $90 \%$ of neurons would be lost without treatment [94]. In contrast, rats with laser-induced glaucoma injected with a viral vector containing CNTF showed only $15 \%$ less retinal ganglion cell death compared to untreated rats [95]. Glial cell line-derived neurotrophic factor (GDNF) signalling has also been shown to indirectly support photoreceptor survival [96], and the anti-inflammatory effect of transduced pigment epithelium-derived factor is protective of retinal ganglion cells in the DBA/2J glaucoma mouse model [97]. As neurotrophic factors innately stimulate neuroprotection, they may be a useful starting point for treatment of retinal degeneration [98]. 
Stem Cell Therapy

Stem cells are able to secrete neurotrophic factors through paracrine action [99]; thus, stem cell therapy may facilitate the neuroprotection of photoreceptors. Intravitreal injections of mesenchymal stem cells engineered to secrete high levels of neurotrophic factors (BDNF, GDNF, and vascular endothelial growth factor [VEGF]) have been shown to significantly extend retinal ganglion cell survival in a rat model (69\% vs. $46 \%$ with placebo, $p=0.0005$ ) [99]. Furthermore, the restoration of degenerating supportive cells with stem cell-derived replacements may protect photoreceptors: insertion of human embryonic stem cellderived RPE cells has been shown to preserve photoreceptor function long term in a rat model [100]. Similar stem cell-derived RPE cells are being trialled in humans: a phase 1 study of PF-05206388 has shown preliminary evidence for the safety and feasibility of this neuroprotective therapy in patients with AMD [101], and ongoing phase 1 and $1 / 2$ a studies are currently examining the safety, tolerability, and initial efficacy of stem cell derivatives ASP7317 and OpRegen in patients with GA $[102,103]$.

\section{Catalases}

Catalases are ubiquitous enzymes that catalyse the breakdown of hydrogen peroxide (a common ROS) to water and oxygen, preventing the cellular damage caused by oxidative stress $[104,105]$. Previous work has shown that catalases protect rat retinas from ischemia/reperfusion damage by reducing oxidative stress [106], and nanoparticle-mediated catalases protect cultured human neurons from oxidative damage and can even restore neuronal morphology [105]. Specific to the human retina, catalases reduce the oxidative stress caused by hyperglycaemia in cultured human retinal cells [107]. Therefore, catalases may be a good neuroprotective option for both stress-associated and chronic neurodegenerative disorders [105].

\section{Heat Shock Proteins}

Heat shock proteins (HSPs) respond to cellular stress by repairing proteins and peptides and degrading irreparable proteins, thus limiting widespread cellular damage [108]. Increasing HSPB5 expression in a transgenic model of Huntington's disease confers neuroprotection through a non-cell autonomous pathway [109]. HSPB5 also plays a role in protecting the outer cells of the retina in response to severe oxidative stress [110]. Although the role of HSPs in neuroprotection and neuroinflammation is not yet fully understood, their functional role in cellular repair and association with areas of inflammation and damage may facilitate neuroprotection [111].

\section{Autophagy}

Autophagy is a process of self-degradation that removes misfolded or aggregated proteins, damaged organelles, and intracellular pathogens $[112,113]$. Rapamycin, a drug that induces autophagy, has been shown to confer neuroprotection in fly and mouse models of Huntington's disease [114]. However, if autophagic recycling becomes imbalanced, it can lead to neuronal cell death; thus, careful control of autophagy is vital $[112,115]$. At present, it is not clear what specific modulation of autophagy is required for neuroprotection [115]; control of autophagy could be a promising future strategy, but further studies are required to establish its role and potential for therapeutic use.

\section{Mechanisms of Neural Damage in GA}

At present, the direct causes of GA and its progression are unknown. Vision loss in patients with GA is directly related to photoreceptor dysfunction and death [116]. There are a number of mechanisms through which photoreceptors can be damaged; these are typically linked to changes in oxygenation or light-induced damage, leading to oxidative stress, proinflammatory cellular activity, and, ultimately, cell death [117-119].

\section{Changes in Oxygenation Level}

The retina is highly metabolically active, meaning that it has a great oxygen demand [120]; this renders it particularly sensitive to changes in oxygenation. Both hypoxia and hyperoxia increase the frequency of cell death in the retina, primarily in the outer nuclear layer [117]. Hypoxia in the retina induces the expression of hypoxia-inducible factor-1 $1 \alpha$, which leads to the expression of VEGF and nitric oxide synthase [120]. VEGF production disrupts the blood-retina barrier and can lead to retinal edema [120], whereas nitric oxide synthase expression increases concentrations of nitric oxide and may directly result in cell death [120]. Furthermore, the activation of glutamate receptors in hypoxic conditions may damage the photoreceptors by initiating a biochemical cascade that increases intracellular calcium levels [120]. Since GA is associated with ischemia [121], photoreceptor damage relating to retinal ischemia due to hypoxia may be especially relevant when considering neuroprotective strategies.

\section{Oxidative Stress}

Oxidative stress is a result of an imbalance in the production and sequestering of ROS [119]. An excess of ROS can damage cellular structures, including membranes, lip- 
ids, proteins, and DNA [119]. The retina is especially vulnerable to oxidative stress because of its rich polyunsaturated lipid membranes and the high metabolic rate of its neurons [76, 122, 123]. Furthermore, mitochondria, which are particularly abundant in photoreceptors, are vulnerable to damage from oxidative stress [123]; there are substantially fewer mitochondria in the RPE of patients with AMD compared with healthy individuals [124]. Oxidative stress plays a key role in a range of retinal diseases, including AMD; thus, treatment strategies that target oxidative stress in the retina may have broad applications for retinal health [125]. One ongoing phase 2 study is examining the safety and efficacy of elamipretide (a mitochondrially targeted antioxidant) in patients with GA [126]. However, the administration of antioxidants has yet to show an effect on the incidence of GA or its progression $[89,127]$. That said, a recent large study $(14,135$ eyes $)$ showed that dietary intake of multiple nutrients (including vitamin $A$, vitamin $B 6, \beta$-carotene, lutein and zeaxanthin, magnesium, and copper) reduces the risk of progression from intermediate AMD to advanced AMD [128].

\section{Proinflammatory Macrophage Activity}

The immune response to oxidative damage can result in an increased presence of proinflammatory macrophages between the RPE and photoreceptor outer segments [118]; over-accumulation of macrophages between the RPE and photoreceptors is associated with the secretion of proinflammatory cytokines [129]. In a mouse model of AMD, retinal infiltration by macrophages preceded the onset of retinal damage, suggesting a causative role [118]. When exposed to proinflammatory cytokines, RPE cells express fewer than usual genes that are critically involved in the visual cycle, epithelial morphology, and phagocytosis [130]. Furthermore, senescent RPE cells upregulate AMD- and GA-associated inflammatory factors (interleukin-6 and interleukin-8), forming a cyclical pattern of damage [131-133]. The evidence linking proinflammatory macrophages to the sites of future AMD development implicates macrophage control as a potential mechanism for neuroprotection [118].

\section{Changes in the RPE}

The RPE acts as a selective barrier and vegetative regulator of the photoreceptor layer [134]; thus, changes in the RPE may have a direct effect on the health of photoreceptors. Age-related changes in the RPE, such as accumulation of lipofuscin, are associated with the pathogenesis of AMD [134]; lipofuscin is phototoxic and has been linked to oxidative changes associated with cell death [134].
Thinning of the RPE is one sign of GA [5, 9-11]; therefore, it is reasonable to assume that other changes in the RPE may play a role in GA-associated photoreceptor death. Further research is needed to establish the precise impact of RPE changes on GA.

\section{Light-Induced Damage}

Light can induce oxidative stress-mediated damage to photoreceptors. Oxidative reactions are apparent in rat retinas after 5 days of constant light exposure [135]. Light wavelengths within the visible spectrum range (415-755 $\mathrm{nm}$ ) are associated with the highest levels of mitochondrial dysfunction in RPE cell cultures that have been modified to mimic ageing [136]. However, a meta-analysis has indicated that exposure to sunlight may not be associated with an increased risk of developing AMD in humans [137]. Although excess light can induce retinal damage, it is unlikely to be a mechanism underlying AMD or the cause of retinal dysfunction in the majority of patients.

\section{The Rationale for Using Neuroprotection to Manage \\ GA}

Primary pathways implicated in the progression of GA are also associated with mechanisms that can damage photoreceptors, such as inflammation, oxidative stress, and blood flow regulation [70]. As neuroprotective agents can protect photoreceptors from damage and increase the survival of neural tissue by preserving neuronal structure and function [70], they are a promising disease management option for GA. Importantly, a neuroprotective mechanism may work independently from the primary disease pathomechanism of GA.

\section{Previously Trialled Neuroprotective Therapies}

Many agents, including apoptosis inhibitors, anti-inflammatory agents, neurotrophic factors, antioxidants, progesterone, ursodeoxycholic acid, and tauroursodeoxycholic acid, have been used to combat neurodegeneration in various clinical settings [85, 98, 138-143]. Although corticosteroids are not traditionally thought of as neuroprotective agents, sustained-release fluocinolone acetonide [144-146] is one example of a corticosteroid formulation that could play a neuroprotective role in retinal diseases because of its anti-inflammatory effects [146]. However, as fluocinolone is a non-specific corticosteroid, it may not sufficiently target GA lesions. Other corticosteroids in AMD have failed to improve visual 





acuity [145, 147]. Several neuroprotective agents have been investigated in GA over the past decade but have typically not advanced to further trials and were largely unsuccessful (Table 1).

\section{Brimonidine}

Brimonidine is a selective $\alpha 2$-adrenergic receptor agonist that has been used in glaucoma for its intraocular pressure-lowering effects $[148,149]$. It is thought that brimonidine may directly interact with $\alpha 2$ receptors, leading to a reduced pathological accumulation of extracellular glutamate and preventing the death of retinal ganglion cells $[149,150]$; the activation of glutamate receptors can damage photoreceptors by increasing intracellular calcium levels [120]. Brimonidine has demonstrated a small, non-significant effect on the slowing GA lesion growth; mean growth from baseline at one year was $\sim 15 \%$ compared with $\sim 22 \%$ in the sham group [151]. In a phase 2 trial of brimonidine for the treatment of GA, there were some discontinuations in the treatment group $(\sim 5 \%)$ due to adverse events. Although these events were not considered treatment-related, around one-quarter of all adverse events were attributed to the injection itself, highlighting the treatment burden associated with frequent intravitreal injections [151]. The lack of significant effect on GA lesion growth indicates that the specific neuroprotective mechanism of brimonidine does not sufficiently overcome the primary pathology of GA.

\section{Tandospirone}

Tandospirone $[152,153]$ is a 5-hydroxytryptamine-1A receptor agonist, which has been shown to protect the RPE in albino and pigmented rats [154]. Tandospirone has a lower treatment burden than intravitreal injections owing to its delivery method (eye drops) and has demonstrated only low-grade adverse events, including eye irritation $(8-10 \%)$, eye pain $(6-7 \%)$, and blepharitis (57\%) [153]. However, its desirable safety profile is outweighed by its lack of efficacy in GA; no difference was observed in GA lesion growth rate between patients who received placebo and patients treated with tandospirone [153]. Furthermore, eye drops are associated with low patient compliance and can be challenging to self-administer [155]. Also, the administration of tandospirone in the form of eye drops may prevent the drug from reaching the retina in sufficient volumes to be effective $[153,156]$.

\section{NT-501}

NT-501 contains two human cell lines that have been genetically modified to secrete human CNTF into the vit- reous cavity at different doses via an implanted device, providing direct retinal access $[157,158]$. High doses of CNTF (20 ng/day) resulted in $96 \%$ of patients with GA losing fewer than three lines of vision (measured using BCVA) versus $75 \%$ of patients who received sham surgery; however, this difference was not statistically significant. There was a statistically significant change in macular volume versus baseline for the low- and high-dose CNTF groups as measured by optical coherence tomography ( $p<0.001$ vs. sham surgery), but it was not possible to establish whether this was due to an increase in retinal cell numbers [158]. As NT-501/CNTF is delivered via an implant, there is a reduced treatment burden for the patient as the implant is only inserted once [158]. No serious adverse events relating to the implant or surgery were reported; however, there were instances of photopsia, miosis, and worsening of pre-existing cataracts in the treated groups. Although the mechanism of action of NT-501 is appropriate for the treatment of GA, it is possible that the choice of growth factor in this trial was not suitable for GA specifically. NT-501 has been more successful in other retinal indications; in patients with macular telangiectasia, CNTF effectively slowed the progression of retinal degeneration [159].

\section{Other Considerations}

The endpoints that the aforementioned clinical trials were structured around may not have been appropriate for detecting improvements in visual function. For example, in a clinical trial of pegcetacoplan (APL-2), an anatomical reduction in GA progression was demonstrated for treated versus sham patients, but there were no efficacy differences for secondary visual endpoints such as BCVA [45]. Ensuring that trials are well designed and sufficiently powered to detect both anatomical and functional endpoints is likely to be crucial in determining the efficacy of potential new treatments for GA. This is especially relevant for treatments with neuroprotective mechanisms as they may be able to maintain visual function even when cells are anatomically dysfunctional.

Furthermore, the point at which treatment begins in clinical trials is critical for progressive diseases such as GA. As current and in-development treatments are not able to reverse photoreceptor death, the level of pre-existing atrophy in patients with advanced GA could limit treatment efficacy. This may partly explain the limited efficacy reported in previous studies of treatments for GA. The recent Classification of Atrophy Meetings (CAM) guidelines [160] may help researchers to identify 
Table 2. Neuroprotective therapies currently under investigation in ocular diseases

\begin{tabular}{|c|c|c|c|c|}
\hline Treatment & Indication & Intervention & Endpoints & Status \\
\hline $\begin{array}{l}\text { CoQ10-MINIACTIVES } \\
\text { (NCT04038034) }\end{array}$ & Glaucoma & $\begin{array}{l}\text { IOP-lowering drugs with } \\
\text { either } 100 \mathrm{mg} \text { b.i.d. oral } \\
\text { administration of CoQ10- } \\
\text { MINIACTIVES or placebo }\end{array}$ & $\begin{array}{l}\text { Pattern electroretinogram amplitude at } 12 \text { months versus } \\
\text { baseline (primary); visual field test; contrast sensitivity; } \\
\text { peripapillary retinal nerve fibre layer thickness by OCT; } \\
\text { macular retinal nerve fibre layer thickness by OCT }\end{array}$ & $\begin{array}{l}\text { Recruiting, } \\
\text { phase N/A }\end{array}$ \\
\hline $\begin{array}{l}\text { Lutein dietary } \\
\text { supplements } \\
\text { (NCT03932305) }\end{array}$ & $\begin{array}{l}\text { Retinal } \\
\text { detachment }\end{array}$ & Lutein vs. placebo & $\begin{array}{l}\text { BCVA at } 6 \text { months versus baseline (primary); retinal } \\
\text { anatomical changes by OCT; contrast sensitivity by Pelli- } \\
\text { Robson chart; quality of life measures (impact of vision } \\
\text { impairment profile) }\end{array}$ & $\begin{array}{l}\text { Active, not } \\
\text { recruiting, } \\
\text { phase N/A }\end{array}$ \\
\hline $\begin{array}{l}\text { NT-501 implant } \\
\text { (NCT02862938) }\end{array}$ & Glaucoma & $\begin{array}{l}\text { NT-501 ECT implant vs. } \\
\text { sham }\end{array}$ & $\begin{array}{l}\text { Visual field (primary); retinal ganglion cell layer thickness } \\
\text { by OCT; retinal nerve fibre layer thickness by OCT; contrast } \\
\text { sensitivity; BCVA; optic nerve head structural change }\end{array}$ & $\begin{array}{l}\text { Active, not } \\
\text { recruiting, } \\
\text { phase } 2\end{array}$ \\
\hline $\begin{array}{l}\text { ACTHAR gel } \\
\text { (NCT01838174) }\end{array}$ & $\begin{array}{l}\text { Acute optic } \\
\text { neuritis }\end{array}$ & $\begin{array}{l}\text { ACTHAR gel versus } \\
\text { intravenous } \\
\text { methylprednisolone }\end{array}$ & $\begin{array}{l}\text { Retinal nerve fibre layer thickness (primary); frequency of } \\
\text { retinal nerve fibre layer swelling; mood, visual function } \\
\text { (NEI-VFQ-25) and quality of life assessment }\end{array}$ & $\begin{array}{l}\text { Recruiting, } \\
\text { phase } 4\end{array}$ \\
\hline
\end{tabular}

BCVA, best corrected visual acuity; b.i.d., twice daily; ECT, encapsulated cell therapy; IOP, intraocular pressure; N/A, not applicable; NEI-VFQ-25, National Eye Institute Visual Function Questionnaire (25 questions); OCT, optical coherence tomography.

patients with nascent GA (or who are at a high risk of developing GA) for inclusion in clinical trials of novel treatments and could result in improved vision outcomes for patients.

\section{The Future Role of Effective Neuroprotection in GA: Redefining the Approach and Conclusions}

GA is associated with considerable disease burden and progression. Despite this, there are currently no approved treatments to prevent the onset or delay the progression of GA. At present, a number of neuroprotective agents are under investigation in other retinal diseases (Table 2), validating the consideration of neuroprotection in GA. Although a neuroprotective mechanism could have a positive impact on the treatment landscape of GA, based on previous clinical trials (Table 1), treatment duration and efficacy need to be improved.

\section{Future Therapeutic Approaches of Neuroprotection in GA}

A treatment's duration of action will need to be considered for future therapies. GA may be similar to diseases in which chronic damage occurs gradually over time; therefore, the duration of action of previously trialled neuroprotective agents may have been too short to combat chronic and ongoing damage. Duration of action could be increased through specific treatment formula- tions or by identifying treatments with superior ocular pharmacokinetics.

Selecting an appropriate target of action may also be critical in future clinical trials. Thinning of the RPE is a known characteristic of GA [5, 9-11]; therefore, targeting the RPE may be appropriate. However, the histopathology of GA lesions shows that the area of photoreceptor loss is much larger than the area of RPE loss [116], and microperimetry has demonstrated that impairment of photoreceptor activity extends beyond the anatomical GA lesion area [161]. If photoreceptor death takes place before the RPE is lost, then the RPE may not be an ideal target for treatment, as irreversible vision loss would have already occurred. That said, the resorption of drusen and loss of the RPE are indicators of GA progression, meaning that photoreceptor death may be secondary to the presence of RPE hypopigmentation [162]. If so, the RPE could still be an ideal target for induced or transduced expression of neuroprotective proteins. One example of a potential target associated with the RPE is the DICER1 pathway. The accumulation of Alu RNA resulting from a DICER1 deficiency in the RPE has been implicated in GA [163-165]; a DICER1 deficit activates inflammasomes, which leads to RPE cell death via activation of caspase- $8[163,164]$. Furthermore, the inhibition of inflammasome components has been shown to prevent RPE degeneration induced by DICER1 loss [163]. As such, there is a rationale for targeting the DICER1 pathway, or another associated neuroprotective protein in the RPE, for the treatment of GA. 
A number of clinical trials in GA have targeted treatment to the complement system. However, given the known ethnic variation in complement polymorphisms [37-40], such a treatment is unlikely to be equally efficacious in all populations. Accordingly, trials of complement inhibitors have shown variable success in delaying the progression of GA (Table 1) [41-43, 45].

An alternative possibility is to focus on a neuroprotective agent that directly protects the photoreceptors, which could delay vision loss despite the breakdown of the choroidal endothelium and choriocapillaris. The photoreceptors, RPE, and choriocapillaris exist in a symbiotic relationship, which breaks down in AMD [162]; detachment of the retina from the choroid leads to photoreceptor death [162]. A neuroprotective agent may prolong the survival and function of photoreceptors despite vascular damage. Although this would not treat the root cause of vision loss, a delay in photoreceptor death may be sufficient to maintain visual function for several years.

Importantly, efficacy should be measured not just using anatomical markers but also by measures of retinal sensitivity, which can be impaired even in regions of the retina that appear anatomically normal [161]. In addition to target selection, it is crucial to consider when to begin treatment; as GA is progressive and irreversible, earlier treatment is likely to preserve better visual function.

\section{Conclusion}

Neuroprotection offers a theoretical mechanism for delaying photoreceptor death; although many clinical trials of neuroprotective factors have been unsuccessful thus far, the mechanism of drug delivery, specificity of treatment and primary endpoint selection may have impacted the outcomes of these trials. Studies focusing on the effect of neurotrophic factors (or other molecules involved in their signalling cascades) could identify a neuroprotective agent with a long duration of action that delays the incidence and/or the progression of GA and, ultimately, the onset of vision loss, providing clinically meaningful benefits for patients.

\section{Acknowledgements}

Medical writing support was provided by Imogen Allred, DPhil, and Tom Priddle, DPhil, of OPEN Health Communications (London, UK), funded by Boehringer Ingelheim.

\section{Conflict of Interest Statement}

H.P.N.S. declares that he is the Editor-In-Chief of the journal Ophthalmic Research, and in addition declares support from the Swiss National Science Foundation, National Center of Competence in Research Molecular Systems Engineering "Molecular Systems Engineering," the Wellcome Trust, and the Foundation Fighting Blindness Clinical Research Institute; declares membership of the Scientific Advisory Board of Astellas Institute for Regenerative Medicine; GenSight Biologics; Ionis Pharmaceuticals, Inc.; Gyroscope Therapeutics Ltd.; Janssen Research \& Development, LLC (Johnson \& Johnson); and Pharma Research \& Early Development (pRED) of F. Hoffmann-La Roche Ltd.; Novartis Pharma AG (CORE); paid consultancy of Boehringer Ingelheim Pharma GmbH \& Co; Gerson Lehrman Group; and Guidepoint; declares membership of the Data Monitoring and Safety Board/ Committee of Belite Bio and ReNeuron Group Plc/Ora Inc. and the Steering Committee of Novo Nordisk (FOCUS trial); is a codirector of the Institute of Molecular and Clinical Ophthalmology Basel (IOB), which is constituted as a non-profit foundation and receives funding from the University of Basel, the University Hospital Basel, Novartis, and the government of Basel-Stadt; and is a principal investigator of grants at the USB sponsored by the following entities: IVERIC bio (Ophthotech Corporation), Kinarus AG, and Novartis Pharma AG. D.B. declares that he is a consultant with Acucela, Alimera Sciences, Allegro, Bayer, EyePoint Pharmaceuticals, ONL Therapeutics, Oxurion, and Takeda; is a consultant and researcher with Adverum, Aerpio Pharmaceuticals, Allergan, Apellis, Boehringer Ingelheim, Chengdu Kanghong, Clearside Biomedical, Genentech/Roche, Kodiak, Novartis, Regeneron, RegenXBIO, Roche, and Santen; and is a researcher with Aerie Pharmaceuticals, Gemini Therapeutics, Graybug Vision, IONIS Pharmaceuticals, Neurotech, Opthea, and Outlook Therapeutics. V.C. and A.G. are employees of Boehringer Ingelheim.

\section{Funding Sources}

Funding was provided by Boehringer Ingelheim.

\section{Author Contributions}

H.P.N.S., D.B., A.G., and V.C. were involved in the conceptual design of the manuscript, drafting and development, and agreement to publish.

References

1 Bird AC, Bressler NM, Bressler SB, Chisholm IH, Coscas G, Davis MD, et al. An international classification and grading system for age-related maculopathy and age-related macular degeneration. The International ARM Epidemiological Study Group. Surv Ophthalmol. 1995 Mar-Apr;39(5):367-74.

2 Lim LS, Mitchell P, Seddon JM, Holz FG, Wong TY. Age-related macular degeneration. Lancet. 2012;379(9827):1728-38. 
3 Ambati J, Atkinson JP, Gelfand BD. Immunology of age-related macular degeneration. Nat Rev Immunol. 2013;13(6):438-51.

4 Wong WL, Su X, Li X, Cheung CM, Klein R, Cheng CY, et al. Global prevalence of age-related macular degeneration and disease burden projection for 2020 and 2040: a systematic review and meta-analysis. Lancet Glob Health. 2014;2(2):e106-16.

5 Boyer DS, Schmidt-Erfurth U, van Lookeren Campagne M, Henry EC, Brittain C. The pathophysiology of geographic atrophy secondary to age-related macular degeneration and the complement pathway as a therapeutic target. Retina. 2017;37(5):819-35.

6 Moutray T, Chakravarthy U. Age-related macular degeneration: current treatment and future options. Ther Adv Chronic Dis. 2011; 2(5):325-31.

7 Yonekawa Y, Kim IK. Clinical characteristics and current treatment of age-related macular degeneration. Cold Spring Harb Perspect Med. 2014;5(1):a017178.

8 Handa JT, Bowes Rickman C, Dick AD, Gorin MB, Miller JW, Toth CA, et al. A systems biology approach towards understanding and treating non-neovascular age-related macular degeneration. Nat Commun. 2019;10(1): 3347.

9 Fleckenstein M, Mitchell P, Freund KB, Sadda S, Holz FG, Brittain C, et al. The progression of geographic atrophy secondary to age-related macular degeneration. Ophthalmology. 2018;125(3):369-90.

10 Katschke KJ, Xi H, Cox C, Truong T, Malato $\mathrm{Y}$, Lee WP, et al. Classical and alternative complement activation on photoreceptor outer segments drives monocyte-dependent retinal atrophy. Sci Rep. 2018;8(1):7348.

11 Nebbioso M, Lambiase A, Cerini A, Limoli PG, La Cava M, Greco A. Therapeutic approaches with intravitreal injections in geographic atrophy secondary to age-related macular degeneration: current drugs and potential molecules. Int J Mol Sci. 2019;20(7): 1693.

12 Chakravarthy U, Bailey CC, Johnston RL, McKibbin M, Khan RS, Mahmood S, et al. Characterizing disease burden and progression of geographic atrophy secondary to agerelated macular degeneration. Ophthalmology. 2018;125(6):842-9.

13 Rim TH, Kawasaki R, Tham Y-C, Kang SW, Ruamviboonsuk P, Bikbov MM, et al. Prevalence and pattern of geographic atrophy in Asia: the Asian Eye Epidemiology Consortium. Ophthalmology. 2020.

14 Brader HS, Ying GS, Martin ER, Maguire MG Characteristics of incident geographic atrophy in the complications of age-related macular degeneration prevention trial. Ophthalmology. 2013;120(9):1871-9.

15 Keenan TD, Agrón E, Domalpally A, Clemons TE, van Asten F, Wong WT, et al. Progression of geographic atrophy in age-related macular degeneration: AREDS2 report number 16 . Ophthalmology. 2018;125(12):1913-28.
16 Finger RP, Wu Z, Luu CD, Kearney F, Ayton LN, Lucci LM, et al. Reticular pseudodrusen: a risk factor for geographic atrophy in fellow eyes of individuals with unilateral choroidal neovascularization. Ophthalmology. 2014; 121(6):1252-6.

17 Balaratnasingam C, Yannuzzi LA, Curcio CA, Morgan WH, Querques G, Capuano V, et al. Associations between retinal pigment epithelium and drusen volume changes during the lifecycle of large drusenoid pigment epithelial detachments. Invest Ophthalmol Vis Sci. 2016;57(13):5479-89.

18 Wightman AJ, Guymer RH. Reticular pseudodrusen: current understanding. Clin Exp Optom. 2019;102(5):455-62.

19 Ueda-Arakawa N, Ooto S, Nakata I, Yamashiro K, Tsujikawa A, Oishi A, et al. Prevalence and genomic association of reticular pseudodrusen in age-related macular degeneration. Am J Ophthalmol. 2013;155(2):260-9.e2.

20 Cho HJ, Yoo SG, Kim HS, Kim JH, Kim CG, Lee TG, et al. Risk factors for geographic atrophy after intravitreal ranibizumab injections for retinal angiomatous proliferation. Am J Ophthalmol. 2015;159(2):285-92.e1.

21 Sivaprasad S, Bird A, Nitiahpapand R, Nicholson L, Hykin P, Chatziralli I. Perspectives on reticular pseudodrusen in age-related macular degeneration. Surv Ophthalmol. 2016 Sep-Oct;61(5):521-37.

22 Spaide RF, Ooto S, Curcio CA. Subretinal drusenoid deposits AKA pseudodrusen. Surv Ophthalmol. 2018 Nov-Dec;63(6):782-815.

23 Roquet W, Roudot-Thoraval F, Coscas G, Soubrane G. Clinical features of drusenoid pigment epithelial detachment in age related macular degeneration. $\mathrm{Br} \mathrm{J}$ Ophthalmol. 2004;88(5):638-42.

24 Sivaprasad S, Chong NV. The complement system and age-related macular degeneration. Eye. 2006;20(8):867-72.

25 Scholl HP, Charbel Issa P, Walier M, Janzer S, Pollok-Kopp B, Börncke F, et al. Systemic complement activation in age-related macular degeneration. PLoS One. 2008;3(7):e2593.

26 Hecker LA, Edwards AO, Ryu E, Tosakulwong N, Baratz KH, Brown WL, et al. Genetic control of the alternative pathway of complement in humans and age-related macular degeneration. Hum Mol Genet. 2009;19(1): 209-15.

27 Charbel Issa P, Chong NV, Scholl HP. The significance of the complement system for the pathogenesis of age-related macular degeneration: current evidence and translation into clinical application. Graefes Arch Clin Exp Ophthalmol. 2011;249(2):163-74.

28 Knickelbein JE, Chan CC, Sen HN, Ferris FL, Nussenblatt RB. Inflammatory mechanisms of age-related macular degeneration. Int Ophthalmol Clin. 2015;55(3):63-78.

29 Dunkelberger JR, Song WC. Complement and its role in innate and adaptive immune responses. Cell Res. 2010;20(1):34-50.
30 Kauppinen A, Paterno JJ, Blasiak J, Salminen A, Kaarniranta K. Inflammation and its role in age-related macular degeneration. Cell Mol Life Sci. 2016;73(9):1765-86.

31 Carter AM. Complement activation: an emerging player in the pathogenesis of cardiovascular disease. Scientifica. 2012;2012: 402783 .

32 Wang J, Jiang J, Zhang Y, Qian YW, Zhang JF, Wang ZL. Retinal and choroidal vascular changes in coronary heart disease: an optical coherence tomography angiography study. Biomed Opt Express. 2019;10(4):1532-44.

33 Biarnés M, Colijn JM, Sousa J, Ferraro LL, Garcia M, Verzijden T, et al. Genotype- and phenotype-based subgroups in geographic atrophy secondary to age-related macular degeneration: the EYE-RISK Consortium. Ophthalmol Retina. 2020;4(12):1129-37.

34 Johnson LV, Leitner WP, Staples MK, Anderson DH. Complement activation and inflammatory processes in drusen formation and age related macular degeneration. Exp Eye Res. 2001;73(6):887-96.

35 Chang MA, Bressler SB, Munoz B, West SK. Racial differences and other risk factors for incidence and progression of age-related macular degeneration: Salisbury Eye Evaluation (SEE) project. Invest Ophthalmol Vis Sci. 2008;49(6):2395-402.

36 Varma R, Choudhury F, Chen S, Wu S, Hsu C, Torres M, et al. Prevalence of age-related macular degeneration in Chinese American adults: the Chinese American Eye Study. JAMA Ophthalmol. 2016;134(5):571-7.

37 Lau L-I, Chen S-J, Cheng C-Y, Yen M-Y, Lee F-L, Lin M-W, et al. Association of the $\mathrm{Y} 402 \mathrm{H}$ polymorphism in complement factor $\mathrm{H}$ gene and neovascular age-related macular degeneration in Chinese patients. Invest Ophthalmol Vis Sci. 2006;47(8):3242-6.

38 Schaumberg DA, Christen WG, Kozlowski P, Miller DT, Ridker PM, Zee RY. A prospective assessment of the $\mathrm{Y} 402 \mathrm{H}$ variant in complement factor $\mathrm{H}$, genetic variants in $\mathrm{C}$-reactive protein, and risk of age-related macular degeneration. Invest Ophthalmol Vis Sci. 2006; 47(6):2336-40.

39 Goverdhan SV, Hannan S, Newsom RB, Luff AJ, Griffiths H, Lotery AJ. An analysis of the $\mathrm{CFH}$ Y402H genotype in AMD patients and controls from the UK, and response to PDT treatment. Eye. 2008;22(6):849-54.

40 Kuo JZ, Wong TY, Ong FS. Genetic risk, ethnic variations and pharmacogenetic biomarkers in age-related macular degeneration and polypoidal choroidal vasculopathy. Expert Rev Ophthalmol. 2013;8(2):127-40.

41 Yehoshua Z, de Amorim Garcia Filho CA, Nunes RP, Gregori G, Penha FM, Moshfeghi AA, et al. Systemic complement inhibition with eculizumab for geographic atrophy in age-related macular degeneration: the COMPLETE study. Ophthalmology. 2014;121(3): 693-701. 
42 Holz FG, Sadda SR, Busbee B, Chew EY, Mitchell P, Tufail A, et al. Efficacy and safety of lampalizumab for geographic atrophy due to age-related macular degeneration: Chroma and Spectri phase 3 randomized clinical trials. JAMA Ophthalmol. 2018;136(6):666-77.

43 Heier JS, Pieramici D, Chakravarthy U, Patel SS, Gupta S, Lotery A, et al. Visual function decline resulting from geographic atrophy: results from the Chroma and Spectri phase 3 trials. Ophthalmol Retina. 2020;4(7):673-88.

44 Jaffe GJ, Westby K, Csaky KG, Monés J, Pearlman JA, Patel SS, et al. C5 inhibitor avacincaptad pegol for geographic atrophy due to age-related macular degeneration: a randomized pivotal phase 2/3 trial. Ophthalmology. 2020.

45 Liao DS, Grossi FV, El Mehdi D, Gerber MR, Brown DM, Heier JS, et al. Complement C3 inhibitor pegcetacoplan for geographic atrophy secondary to age-related macular degeneration: a randomized phase 2 trial. Ophthalmology. 2020;127(2):186-95.

46 Klein R, Wang Q, Klein BE, Moss SE, Meuer $\mathrm{SM}$. The relationship of age-related maculopathy, cataract, and glaucoma to visual acuity. Invest Ophthalmol Vis Sci. 1995;36(1):18291.

47 Sunness JS, Bressler NM, Tian Y, Alexander J, Applegate CA. Measuring geographic atrophy in advanced age-related macular degeneration. Invest Ophthalmol Vis Sci. 1999; 40(8):1761-9.

48 Carlton J, Barnes S, Haywood A. Patient perspectives in geographic atrophy (GA): exploratory qualitative research to understand the impact of GA for patients and their families. Br Ir Orthop J. 2019;15(1):133-41.

49 Sivaprasad S, Tschosik EA, Guymer RH, Kapre A, Suñer IJ, Joussen AM, et al. Living with geographic atrophy: an ethnographic study. Ophthalmol Ther. 2019;8(1):115-24.

50 Burguera-Gimenez N, Garcia-Lazaro S, Espana-Gregori E, Gallego-Pinazo R, Burguera-Gimenez N, Rodriguez-Vallejo M, et al. Multimodal evaluation of visual function in geographic atrophy versus normal eyes. Clin Ophthalmol. 2020;14:1533-45.

51 Varma R, Souied EH, Tufail A, Tschosik E, Ferrara D, Zhang J, et al. Maximum reading speed in patients with geographic atrophy secondary to age-related macular degeneration. Invest Ophthalmol Vis Sci. 2018;59(4): AMD195-201.

52 Sunness JS, Gonzalez-Baron J, Applegate CA, Bressler NM, Tian Y, Hawkins B, et al. Enlargement of atrophy and visual acuity loss in the geographic atrophy form of age-related macular degeneration. Ophthalmology. 1999; 106(9):1768-79.

53 Taylor DJ, Smith ND, Binns AM, Crabb DP. The effect of non-neovascular age-related macular degeneration on face recognition performance. Graefes Arch Clin Exp Ophthalmol. 2018;256(4):815-21.
54 Patel PJ, Ziemssen F, Ng E, Muthutantri A, Silverman D, Tschosik EA, et al. Burden of illness in geographic atrophy: a study of visionrelated quality of life and health care resource use. Clin Ophthalmol. 2020;14:15-28.

55 Rovner BW, Casten RJ, Tasman WS. Effect of depression on vision function in age-related macular degeneration. Arch Ophthalmol. 2002;120(8):1041-4.

56 Coleman AL, Stone K, Ewing SK, Nevitt M, Cummings S, Cauley JA, et al. Higher risk of multiple falls among elderly women who lose visual acuity. Ophthalmology. 2004;111(5): $857-62$.

57 Künzel SH, Möller PT, Lindner M, Goerdt L, Nadal J, Schmid M, et al. Determinants of quality of life in geographic atrophy secondary to age-related macular degeneration. Invest Ophthalmol Vis Sci. 2020;61(5):63.

58 Sacconi R, Corbelli E, Querques L, Bandello F, Querques G. A review of current and future management of geographic atrophy. Ophthalmol Ther. 2017;6(1):69-77.

59 AREDS Research Group. The Age-Related Eye Disease Study (AREDS): design implications. AREDS report no. 1. Control Clin Trials. 1999;20(6):573-600.

60 AREDS Research Group. Risk factors associated with age-related macular degeneration. A case-control study in the age-related eye disease study: Age-Related Eye Disease Study report number 3. Ophthalmology. 2000; 107(12):2224-32.

61 Group AR, Chew EY, Clemons T, SanGiovanni JP, Danis R, Domalpally A, et al. The Age-Related Eye Disease Study 2 (AREDS2): study design and baseline characteristics (AREDS2 report number 1). Ophthalmology. 2012;119(11): 2282-9.

62 Ratnayaka JA, Lotery AJ. Challenges in studying geographic atrophy (GA) age-related macular degeneration: the potential of a new mouse model with GA-like features. Neural Regen Res. 2020;15(5):863-4.

63 Somani R, Grant PJ, Kain K, Catto AJ, Carter $\mathrm{AM}$. Complement $\mathrm{C} 3$ and $\mathrm{C}$-reactive protein are elevated in South Asians independent of a family history of stroke. Stroke. 2006;37(8):2001-6.

64 Joachim N, Mitchell P, Younan C, Burlutsky G, Cheng C-Y, Cheung CMG, et al. Ethnic variation in early age-related macular degeneration lesions between White Australians and Singaporean Asians. Invest Ophthalmol Vis Sci. 2014;55(7):4421-9.

65 Cheung CMG, Gan A, Yanagi Y, Wong TY, Spaide R. Association between choroidal thickness and drusen subtypes in age-related macular degeneration. Ophthalmol Retina. 2018;2(12):1196-205.

66 NCT03845582. A phase 2/3 multicenter, randomized, double-masked, parallel-group, placebo-controlled study to investigate the safety, pharmacokinetics, tolerability, and efficacy of ALK-001 in geographic atrophy secondary to age-related macular degeneration. Available from: https://clinicaltrials.gov/ct2/ show/study/NCT03845582.
67 NCT02684578. METforMIN: metformin administration for the minimization of geographic atrophy progression in patients with age-related macular degeneration. Available from: https://clinicaltrials.gov/ct2/show/ study/NCT02684578.

68 Bavik C, Henry SH, Zhang Y, Mitts K, McGinn T, Budzynski E, et al. Visual cycle modulation as an approach toward preservation of retinal integrity. PLoS One. 2015;10(5): e0124940.

69 Dugel PU, Novack RL, Csaky KG, Richmond PP, Birch DG, Kubota R. Phase II, randomized, placebo-controlled, 90-day study of emixustat hydrochloride in geographic atrophy associated with dry age-related macular degeneration. Retina. 2015;35(6):1173-83.

70 Patel HR, Hariprasad SM, Eichenbaum D. Geographic atrophy: clinical impact and emerging treatments. Ophthalmic Surg Lasers Imaging Retina. 2015;46(1):8-13.

71 Saad L, Washington I. Can vitamin A be improved to prevent blindness due to age-related macular degeneration, Stargardt disease and other retinal dystrophies? Adv Exp Med Biol. 2016;854:355-61.

72 Vajda FJ. Neuroprotection and neurodegenerative disease. J Clin Neurosci. 2002;9(1):4-

73 LaVail M, Anderson R. Chapter 6: restoring vision to the blind: neuroprotection. Trans Vis Sci Tech. 2014;3(7):8.

74 Aktas O, Ullrich O, Infante-Duarte C, Nitsch R, Zipp F. Neuronal damage in brain inflammation. Arch Neurol. 2007;64(2):185-9.

75 Glass CK, Saijo K, Winner B, Marchetto MC, Gage FH. Mechanisms underlying inflammation in neurodegeneration. Cell. 2010;140(6): 918-34.

76 Abu-Amero KK, Kondkar AA, Chalam KV Resveratrol and ophthalmic diseases. Nutrients. 2016;8(4):200.

77 Lassmann H, van Horssen J. Oxidative stress and its impact on neurons and glia in multiple sclerosis lesions. Biochim Biophys Acta. 2016; 1862(3):506-10.

78 Casson RJ, Chidlow G, Ebneter A, Wood JP, Crowston J, Goldberg I. Translational neuroprotection research in glaucoma: a review of definitions and principles. Clin Exp Ophthalmol. 2012 May-Jun;40(4):350-7.

79 Campos-Esparza MR, Sánchez-Gómez MV, Matute C. Molecular mechanisms of neuroprotection by two natural antioxidant polyphenols. Cell Calcium. 2009;45(4):358-68.

80 Jun-Long H, Yi L, Bao-Lian Z, Jia-Si L, Ning $Z$, Zhou-Heng Y, et al. Necroptosis signaling pathways in stroke: from mechanisms to therapies. Curr Neuropharmacol. 2018;16(9): 1327-39.

81 Wu Y, Song J, Wang Y, Wang X, Culmsee C, Zhu C. The potential role of ferroptosis in neonatal brain injury. Front Neurosci. 2019; 13:115. 
82 Duan J, Cui J, Yang Z, Guo C, Cao J, Xi M, et al. Neuroprotective effect of Apelin 13 on ischemic stroke by activating AMPK/GSK$3 \beta / \mathrm{Nrf2}$ signaling. J Neuroinflammation. 2019;16(1):24.

83 Zhou H, Wang J, Jiang J, Stavrovskaya IG, Li $\mathrm{M}, \mathrm{Li} \mathrm{W}$, et al. N-acetyl-serotonin offers neuroprotection through inhibiting mitochondrial death pathways and autophagic activation in experimental models of ischemic injury. J Neurosci. 2014;34(8):2967-78.

84 Nguyen TL, Kim CK, Cho JH, Lee KH, Ahn JY. Neuroprotection signaling pathway of nerve growth factor and brain-derived neurotrophic factor against staurosporine induced apoptosis in hippocampal H19-7/IGF-IR [corrected]. Exp Mol Med. 2010;42(8):58395.

85 Lalkovičová M, Danielisová V. Neuroprotection and antioxidants. Neural Regen Res. 2016;11(6):865-74.

86 Huang HF, Guo F, Cao YZ, Shi W, Xia Q. Neuroprotection by manganese superoxide dismutase (MnSOD) mimics: antioxidant effect and oxidative stress regulation in acute experimental stroke. CNS Neurosci Ther. 2012;18(10):811-8.

87 Gherghel D, Griffiths HR, Hilton EJ, Cunliffe IA, Hosking SL. Systemic reduction in glutathione levels occurs in patients with primary open-angle glaucoma. Invest Ophthalmol Vis Sci. 2005;46(3):877-83.

88 Chang JS, Lee YJ, Wilkie DA, Lin CT. The neuroprotective and antioxidative effects of submicron and blended Lycium barbarum in experimental retinal degeneration in rats. J Vet Med Sci. 2018;80(7):1108-15.

89 Lindblad AS, Lloyd PC, Clemons TE, Gensler GR, Ferris FL 3rd, Klein ML, et al. Change in area of geographic atrophy in the Age-Related Eye Disease Study: AREDS report number 26. Arch Ophthalmol. 2009;127(9):1168-74.

90 Wong WT, Kam W, Cunningham D, Harrington $\mathrm{M}$, Hammel $\mathrm{K}$, Meyerle $\mathrm{CB}$, et al. Treatment of geographic atrophy by the topical administration of OT-551: results of a phase II clinical trial. Invest Ophthalmol Vis Sci. 2010;51(12):6131-9.

91 Fargali S, Sadahiro M, Jiang C, Frick AL, Indall T, Cogliani V, et al. Role of neurotrophins in the development and function of neural circuits that regulate energy homeostasis. J Mol Neurosci. 2012;48(3):654-9.

92 Lipinski DM, Barnard AR, Singh MS, Martin C, Lee EJ, Davies WIL, et al. CNTF gene therapy confers lifelong neuroprotection in a mouse model of human retinitis pigmentosa. Mol Ther. 2015;23(8):1308-19.

93 Kassen SC, Thummel R, Campochiaro LA, Harding MJ, Bennett NA, Hyde DR. CNTF induces photoreceptor neuroprotection and Müller glial cell proliferation through two different signaling pathways in the adult zebrafish retina. Exp Eye Res. 2009;88(6):1051-64.
94 Cheng L, Sapieha P, Kittlerova P, Hauswirth WW, Di Polo A. TrkB gene transfer protects retinal ganglion cells from axotomy-induced death in vivo. J Neurosci. 2002;22(10): 3977-86.

95 Pease ME, Zack DJ, Berlinicke C, Bloom K, Cone F, Wang Y, et al. Effect of CNTF on retinal ganglion cell survival in experimental glaucoma. Invest Ophthalmol Vis Sci. 2009; 50(5):2194-200.

96 Hauck SM, Kinkl N, Deeg CA, Swiatek-de Lange M, Schöffmann S, Ueffing M. GDNF family ligands trigger indirect neuroprotective signaling in retinal glial cells. Mol Cell Biol. 2006;26(7):2746-57.

97 Zhou X, Li F, Kong L, Chodosh J, Cao W. Anti-inflammatory effect of pigment epithelium-derived factor in DBA/2J mice. $\mathrm{Mol}$ Vis. 2009; 15:438-50.

98 Kimura A, Namekata K, Guo X, Harada C, Harada T. Neuroprotection, growth factors and BDNF-TrkB signalling in retinal degeneration. Int J Mol Sci. 2016;17(9).

99 Levkovitch-Verbin H, Sadan O, Vander S, Rosner M, Barhum Y, Melamed E, et al. Intravitreal injections of neurotrophic factors secreting mesenchymal stem cells are neuroprotective in rat eyes following optic nerve transection. Invest Ophthalmol Vis Sci. 2010;51(12):6394-400.

100 McGill TJ, Bohana-Kashtan O, Stoddard JW, Andrews MD, Pandit N, RosenbergBelmaker LR, et al. Long-term efficacy of GMP grade xeno-free hESC-Derived RPE cells following transplantation. Transl Vis Sci Technol. 2017;6(3):17.

101 da Cruz L, Fynes K, Georgiadis O, Kerby J, Luo YH, Ahmado A, et al. Phase 1 clinical study of an embryonic stem cell-derived retinal pigment epithelium patch in age-related macular degeneration. Nat Biotechnol. 2018;36(4):328-37.

102 NCT02286089. Phase I/IIa dose escalation safety and efficacy study of human embryonic stem cell-derived retinal pigment epithelium cells transplanted subretinally in patients with advanced dry-form age-related macular degeneration (geographic atrophy) Available from: https://www.clinicaltrials. gov/ct2/show/NCT02286089 Accessed 2021 Apr.

103 NCT03178149. A phase 1b, multicenter, dose escalation, evaluation of safety and tolerability of ASP7317 for geographic atrophy secondary to age-related macular degeneration. Available from: https://clinicaltrials. gov/ct2/show/NCT03178149 Accessed 2021 Apr.

104 Chelikani P, Fita I, Loewen PC. Diversity of structures and properties among catalases. Cell Mol Life Sci. 2004;61(2):192-208.

105 Singhal A, Morris VB, Labhasetwar V, Ghorpade A. Nanoparticle-mediated catalase delivery protects human neurons from oxidative stress. Cell Death Dis. 2013;4(11): e903.
106 Chen B, Tang L. Protective effects of catalase on retinal ischemia/reperfusion injury in rats. Exp Eye Res. 2011;93(5):599-606.

107 Giordano CR, Roberts R, Krentz KA, Bissig D, Talreja D, Kumar A, et al. Catalase therapy corrects oxidative stress-induced pathophysiology in incipient diabetic retinopathy. Invest Ophthalmol Vis Sci. 2015;56(5): 3095-102.

108 Ikwegbue PC, Masamba P, Oyinloye BE, Kappo AP. Roles of heat shock proteins in apoptosis, oxidative stress, human inflammatory diseases, and cancer. Pharmaceuticals. 2017;11(1):2.

109 Oliveira AO, Osmand A, Outeiro TF Muchowski PJ, Finkbeiner S. aB-Crystallin overexpression in astrocytes modulates the phenotype of the BACHD mouse model of Huntington's disease. Hum Mol Genet. 2016;25(9):1677-89.

110 Sreekumar PG, Kannan R, Kitamura M, Spee C, Barron E, Ryan SJ, et al. aB crystallin is apically secreted within exosomes by polarized human retinal pigment epithelium and provides neuroprotection to adjacent cells. PLoS One. 2010;5(10):e12578.

111 Dukay B, Csoboz B, Tóth ME. Heat-shock proteins in neuroinflammation. Front Pharmacol. 2019;10:920.

112 Cherra SJ 3rd, Chu CT. Autophagy in neuroprotection and neurodegeneration: a question of balance. Future Neurol. 2008; 3(3):309-23.

113 Glick D, Barth S, Macleod KF. Autophagy: cellular and molecular mechanisms. J Pathol. 2010;221(1):3-12.

114 Ravikumar B, Vacher C, Berger Z, Davies JE, Luo S, Oroz LG, et al. Inhibition of mTOR induces autophagy and reduces toxicity of polyglutamine expansions in fly and mouse models of Huntington disease. Nat Genet. 2004;36(6):585-95.

115 Gunn A, Singh A, Diao A, Chen R. Pharmacological modulation of autophagy for neuroprotection in ischaemic stroke. J Exp Stroke Transl Med. 2018;11:1-10.

116 Bird AC, Phillips RL, Hageman GS. Geographic atrophy: a histopathological assessment. JAMA Ophthalmol. 2014;132(3):33845.

117 Wellard J, Lee D, Valter K, Stone J. Photoreceptors in the rat retina are specifically vulnerable to both hypoxia and hyperoxia. Vis Neurosci. 2005 Jul-Aug;22(4):501-7.

118 Cruz-Guilloty F, Saeed AM, Echegaray JJ, Duffort S, Ballmick A, Tan Y, et al. Infiltration of proinflammatory M1 macrophages into the outer retina precedes damage in a mouse model of age-related macular degeneration. Int J Inflam. 2013;2013:503725.

119 Pizzino G, Irrera N, Cucinotta M, Pallio G Mannino F, Arcoraci V, et al. Oxidative stress: harms and benefits for human health Oxid Med Cell Longev. 2017;2017:8416763. 
120 Kaur C, Foulds WS, Ling EA. Hypoxia-ischemia and retinal ganglion cell damage. Clin Ophthalmol. 2008;2(4):879-89.

121 Coleman DJ, Silverman RH, Rondeau MJ, Lloyd HO, Khanifar AA, Chan RV. Age-related macular degeneration: choroidal ischaemia? Br J Ophthalmol. 2013;97(8):1020-3.

122 Aboualizadeh E, Ranji M, Sorenson CM, Sepehr R, Sheibani N, Hirschmugl CJ. Retinal oxidative stress at the onset of diabetes determined by synchrotron FTIR widefield imaging: towards diabetes pathogenesis. Analyst. 2017;142(7):1061-72.

123 Eells JT. Mitochondrial dysfunction in the aging retina. Biology. 2019;8(2):31.

124 Feher J, Kovacs I, Artico M, Cavallotti C, Papale A, Balacco Gabrieli C. Mitochondrial alterations of retinal pigment epithelium in age-related macular degeneration. Neurobiol Aging. 2006;27(7):983-93.

125 Masuda T, Shimazawa M, Hara H. Retinal diseases associated with oxidative stress and the effects of a free radical scavenger (edaravone). Oxid Med Cell Longev. 2017;2017:9208489.

126 A phase 2 randomized, double-masked, Placebo-controlled clinical study to evaluate the safety, efficacy and pharmacokinetics of elamipretide in subjects with age-related macular degeneration with non-central geographic atrophy. Available from: https:// clinicaltrials.gov/ct2/show/NCT03891875 Accessed 2020 Jan 27.

127 AREDS2 Research Group. Lutein + zeaxanthin and omega- 3 fatty acids for age-related macular degeneration: the Age-Related Eye Disease Study 2 (AREDS2) randomized clinical trial. JAMA. 2013;309(19):2005-15.

128 Agrón E, Mares J, Clemons TE, Swaroop A, Chew EY, Keenan TDL. Dietary nutrient intake and progression to late age-related macular degeneration in the Age-Related Eye Disease Studies 1 and 2. Ophthalmology. 2020.

129 Cruz CM, Rinna A, Forman HJ, Ventura AL, Persechini PM, Ojcius DM. ATP activates a reactive oxygen species-dependent oxidative stress response and secretion of proinflammatory cytokines in macrophages. J Biol Chem. 2007;282(5):2871-9.

130 Kutty RK, Samuel W, Boyce K, Cherukuri A, Duncan T, Jaworski C, et al. Proinflammatory cytokines decrease the expression of genes critical for RPE function. Mol Vis. 2016;22:1156-68.

131 Goverdhan SV, Ennis S, Hannan SR, Madhusudhana KC, Cree AJ, Luff AJ, et al. Interleukin-8 promoter polymorphism $-251 \mathrm{~A} / \mathrm{T}$ is a risk factor for age-related macular degeneration. Br J Ophthalmol. 2008;92(4): 537-40.

132 Marazita MC, Dugour A, Marquioni-Ramella MD, Figueroa JM, Suburo AM. Oxidative stress-induced premature senescence dysregulates VEGF and CFH expression in retinal pigment epithelial cells: implications for age-related macular degeneration. Redox Biol. 2016;7:78-87.
133 Krogh Nielsen M, Subhi Y, Molbech CR, Falk MK, Nissen MH, Sørensen TL. Systemic levels of interleukin- 6 correlate with progression rate of geographic atrophy secondary to age-related macular degeneration. Invest Ophthalmol Vis Sci. 2019;60(1):202-8.

134 Boulton M, Dayhaw-Barker P. The role of the retinal pigment epithelium: topographical variation and ageing changes. Eye. 2001; 15(Pt 3):384-9.

135 Benedetto MM, Contin MA. Oxidative stress in retinal degeneration promoted by constant LED light. Front Cell Neurosci. 2019;13:139.

136 Marie M, Bigot K, Angebault C, Barrau C, Gondouin P, Pagan D, et al. Light action spectrum on oxidative stress and mitochondrial damage in A2E-loaded retinal pigment epithelium cells. Cell Death Dis. 2018;9(3): 287.

137 Zhou H, Zhang H, Yu A, Xie J. Association between sunlight exposure and risk of agerelated macular degeneration: a meta-analysis. BMC Ophthalmol. 2018;18(1):331.

138 Jiang N, Chopp M, Stein D, Feit H. Progesterone is neuroprotective after transient middle cerebral artery occlusion in male rats. Brain Res. 1996;735(1):101-7.

139 Robertson GS, Crocker SJ, Nicholson DW, Schulz JB. Neuroprotection by the inhibition of apoptosis. Brain Pathol. 2000;10(2): 283-92.

140 Rodrigues CM, Spellman SR, Solá S, Grande AW, Linehan-Stieers C, Low WC, et al. Neuroprotection by a bile acid in an acute stroke model in the rat. J Cereb Blood Flow Metab. 2002;22(4):463-71.

141 Elewa HF, Hilali H, Hess DC, Machado LS, Fagan SC. Minocycline for short-term neuroprotection. Pharmacotherapy. 2006;26(4): 515-21.

142 Stone LL, Grande A, Low WC. Neural repair and neuroprotection with stem cells in ischemic stroke. Brain Sci. 2013;3(2):599-614.

143 Cheng F, Ma C, Sun L, Zhang X, Zhai C, Li $\mathrm{C}$, et al. Synergistic neuroprotective effects of Geniposide and ursodeoxycholic acid in hypoxia-reoxygenation injury in SH-SY5Y cells. Exp Ther Med. 2018;15(1):320-6.

144 NCT00695318. Fluocinolone acetonide intravitreal inserts in geographic atrophy. Available from: https://clinicaltrials.gov/ct2/ show/NCT00695318 Accessed 2020 Apr 7.

145 Jonas JB, Spandau UH, Kamppeter BA, Harder B. Follow-up after intravitreal triamcinolone acetonide for exudative age-related macular degeneration. Eye. 2007;21(3):38794.

146 Glybina IV, Kennedy A, Ashton P, Abrams GW, Iezzi R. Intravitreous delivery of the corticosteroid fluocinolone acetonide attenuates retinal degeneration in S334ter-4 rats. Invest Ophthalmol Vis Sci. 2010;51(8): 4243-52.
147 Kuppermann BD, Goldstein M, Maturi RK Pollack A, Singer M, Tufail A, et al. Dexamethasone intravitreal implant as adjunctive therapy to ranibizumab in neovascular age-related macular degeneration: a multicenter randomized controlled trial. Ophthalmologica. 2015;234(1):40-54.

148 NCT02087085. A safety and efficacy study of brimonidine intravitreal implant in geographic atrophy secondary to agerelated macular degeneration. Available from: https://clinicaltrials.gov/ct2/show/ NCT02087085 Accessed 2020 Apr 7.

149 Yoles E, Wheeler LA, Schwartz M. Alpha2adrenoreceptor agonists are neuroprotective in a rat model of optic nerve degeneration. Invest Ophthalmol Vis Sci. 1999;40(1): 65-73.

150 Doozandeh A, Yazdani S. Neuroprotection in glaucoma. J Ophthalmic Vis Res. 2016 Apr-Jun;11(2):209-20.

151 Kuppermann BD, Patel SS, Boyer DS, Augustin AJ, Freeman WR, Kerr KJ, et al. Phase 2 study of the safety and efficacy of brimonidine drug delivery system (Brimo Dds) generation 1 in patients with geographic atrophy secondary to age-related macular degeneration. Retina. 2021 Jan;41(1):144-155.

152 NCT00890097. Geographic atrophy treatment evaluation (GATE). Available from: https://clinicaltrials.gov/ct2/show/ NCT00890097. Accessed 2020 Apr 7.

153 Jaffe GJ, Schmitz-Valckenberg S, Boyer D, Heier J, Wolf-Schnurrbusch U, Staurenghi $\mathrm{G}$, et al. Randomized trial to evaluate tandospirone in geographic atrophy secondary to age-related macular degeneration: the GATE Study. Am J Ophthalmol. 2015; 160(6):1226-34.

154 Collier RJ, Patel Y, Martin EA, Dembinska O, Hellberg M, Krueger DS, et al. Agonists at the serotonin receptor $\left(5-\mathrm{HT}_{1 \mathrm{~A}}\right)$ protect the retina from severe photo-oxidative stress. Invest Ophthalmol Vis Sci. 2011;52(5): 2118-26.

155 Robin A, Grover DS. Compliance and adherence in glaucoma management. Indian J Ophthalmol. 2011;59(Suppl 1):S93-6.

156 Gaudana R, Ananthula HK, Parenky A, Mitra AK. Ocular drug delivery. AAPS J. 2010 12(3):348-60.

157 NCT00447954. A Study of an encapsulated cell technology (ECT) implant for patients with atrophic macular degeneration. Available from: https://clinicaltrials.gov/ ct2/show/NCT00447954 Accessed 2020 Apr 7.

158 Zhang K, Hopkins JJ, Heier JS, Birch DG, Halperin LS, Albini TA, et al. Ciliary neurotrophic factor delivered by encapsulated cell intraocular implants for treatment of geographic atrophy in age-related macular degeneration. Proc Natl Acad Sci U S A. 2011; 108(15):6241-5. 
159 Chew EY, Clemons TE, Jaffe GJ, Johnson CA, Farsiu S, Lad EM, et al. Effect of ciliary neurotrophic factor on retinal neurodegeneration in patients with macular telangiectasia type 2: a randomized clinical trial. Ophthalmology. 2019;126(4):540-9.

160 Sadda SR, Guymer R, Holz FG, SchmitzValckenberg S, Curcio CA, Bird AC, et al. Consensus definition for atrophy associated with age-related macular degeneration on OCT: classification of atrophy report 3 . Ophthalmology. 2018;125(4):537-48.
161 Meleth AD, Mettu P, Agrón E, Chew EY, Sadda SR, Ferris FL, et al. Changes in retinal sensitivity in geographic atrophy progression as measured by microperimetry. Invest Ophthalmol Vis Sci. 2011;52(2):1119-26.

162 Bhutto I, Lutty G. Understanding age-related macular degeneration (AMD): relationships between the photoreceptor/retinal pigment epithelium/Bruch's membrane/ choriocapillaris complex. Mol Aspects Med. 2012;33(4):295-317.

163 Tarallo V, Hirano Y, Gelfand BD, Dridi S, Kerur N, Kim Y, et al. DICER1 loss and Alu RNA induce age-related macular degeneration via the NLRP3 inflammasome and MyD88. Cell. 2012;149(4):847-59.
164 Kim Y, Tarallo V, Kerur N, Yasuma T, Gelfand BD, Bastos-Carvalho A, et al. DICER1/ Alu RNA dysmetabolism induces caspase8-mediated cell death in age-related macular degeneration. Proc Natl Acad Sci U S A. 2014;111(45):16082-7.

165 Kaarniranta K, Pawlowska E, Szczepanska J, Blasiak J. DICER1 in the pathogenesis of age-related macular degeneration (AMD): Alu RNA accumulation versus miRNA dysregulation. Aging Dis. 2020;11(4):851-62. 